\title{
DISPERSÃO DE SEMENTES DE VISMIA CAYENNENSIS (JACQ.) PERS. (GUTTIFERAE) POR MORCEGOS NA REGIÃO DE MANAUS, AMAZONAS.
}

\author{
Jader Marinho-Filho ${ }^{1}$ \\ João Vasconcellos-Neto ${ }^{2}$
}

Recebido em 24.05.93. Aceito em 09.05.94.

\begin{abstract}
RESUMO - (Dispersão de sementes de Vismia cayennensis (Jacq.) Pers (Guttiferae) por morcegos na região de Manaus, Amazonas). Estudou-se o comportamento alimentar de morcegos e o seu papel na dispersão de sementes de Vismia cayennensis na região de Manaus, Amazonas. As características da planta e dos frutos correspondem à síndrome de quiropterocoria. Cinco espécies de morcegos filostomídeos se alimentaram dos frutos: Sturnira lilium, Sturnira tildae, Artibeus concolor, Carollia perspicillata e Rhinophylla pumilio. Aparentemente, há uma relação entre o comportamento de forrageamento em grupos e a maior disponibilidade de frutos na primeira parte da noite. O comportamento alimentar foi semelhante para todas as espécies de morcegos, variando em função do modo de apresentação dos frutos. Os testes de germinação e os padrões de distribuição das plantas indicam que morcegos são os dispersores efetivos de V. cayennensis.
\end{abstract}

Palavras-chave: morcegos filostomídeos, comportamento alimentar, quiropterocoria, Vismia cayennensis, Amazônia.

\begin{abstract}
Seed dispersal of Vismia cayennensis (Jacq.) Pers (Guttiferae) by bats in Manaus, Amazonas). We studied the feeding behavior of bats and their role in the seed dispersal of Vismia cayennensis in Manaus region, Amazonas State, northern Brazil. The characteristics of the plant and its fruits fit the chiropterocory syndrome. Five species of phyllostomid bats fed on Vismia fruits: Sturnira lilium, Sturnira tildae, Artibeus concolor, Carollia perspicillata and Rhinophylla pumilio. Apparently there is a relationship between flock foraging behavior and fruit availability in early night. The feeding behavior was similar for all bat species, varying with the presentation mode of the fruits. Seed germination tests and the distributional patterns of the plants indicate that bats are the dispersers of $V$. cayennensis.
\end{abstract}

Key words: phyllostomid bats, feeding behavior, quiropterocory, Vismia cayennensis, Amazon.

\footnotetext{
' Departamento de Zoologia, IB, Universidade de Brasília, Caixa Postal 153074, 70910-900, Brasília-DF, Brasil.

${ }^{2}$ Departamento de Zoologia, IB, Universidade Estadual de Campinas, Caixa Postal 6109, 13081-970 Campinas-SP, Brasil.
} 


\section{Introdução}

A dispersão de sementes de angiospermas pode ser realizada tanto por agentes físicos quanto por animais (van der Pijl 1972). De modo geral, a dispersão efetiva dos propágulos de uma espécie vegetal freqüentemente envolve estreitas relações entre as plantas e seus agentes dispersores (e.g. McKey 1975, Janzen 1983). A expressão disso é o conjunto de adaptações que plantas apresentam no sentido de um melhor ajuste para essa relação. No caso de espécies cujas sementes são dispersas por animais, por exemplo, estas adaptações estão associadas principalmente com a atração e a recompensa de seus dispersores potenciais. Os conjuntos de características e adaptações moldados pela interação planta-agente dispersor são denominados síndromes de dispersão (van der Pijl, 1972). Há relativamente poucos estudos detalhados sobre a história natural e a ecologia das interações entre frugívoros e as sementes que eles dispersam. A maioria dos trabalhos refere-se a aves frugívoras, registrando basicamente a utilização de certas espécies de frutos como alimento para os animais (ver Janzen 1983 para uma revisão do assunto). Morcegos têm sido considerados entre os mais importantes dispersores de sementes da região neotropical (e.g. van der Pijl 1972; Janzen 1976, Bonaccorso 1979). No Brasil, porém, afora alguns resumos apresentados em congressos, poucos estudos apresentaram dados sobre a utilização de frutos por morcegos (e.g. Carvalho 1961, Reis \& Guillaumet 1983, Marinho-Filho 1990), e apenas um trabalho (Uieda \& Vasconcellos Neto 1985) discutiu mais pormenorizadamente a dispersão de duas espécies de Solanum por morcegos na região de Manaus.

O presente trabalho corresponde ao estudo do caso da dispersão de sementes de Vismia cayennensis (Jacq.) Pers. (Guttiferae), na região de Manaus, Amazonas.

\section{Material e métodos}

O trabalho de campo foi realizado durante o mês de julho de 1981, correspondente ao pico de frutificação de Vismia cayennensis, na Estação Experimental de Silvicultura Tropical do Instituto Nacional de Pesquisas da Amazônia (02 ${ }^{0} 37$ 'S $60^{\circ} 03^{\prime} \mathrm{W}$ ), em áreas de capoeira e borda de mata de terra firme.

Ao início do estudo, foram isolados com sacos de papel diversos frutos de $V$. cayennensis em diferentes estádios de desenvolvimento, para evitar sua predação ou utilização prematura por animais. Foram coletados alguns frutos ainda verdes e outros maduros, que foram medidos, pesados e tiveram sua concentração de açúcares aferida com refratômetro manual. Na última semana de julho (lua nova), foram feitas cinco sessões de observação e coleta noturnas. Estas sessões eram iniciadas às 19:30 h e encerradas por volta da meia-noite, com exceção da última noite, em que as observações se estenderam das 18:00 às 06:00 h da manhã seguinte, perfazendo aproximadamente 30 horas de observação. Antes do anoitecer, eram retirados os sacos de papel dos frutos amadurecidos deixando-os acessíveis às visitas dos morcegos. Para pos- 
sibilitar melhor observação, usaram-se lanternas com pilhas fracas, ou um anteparo para evitar a iluminação direta dos frutos. Considerou-se como uma visita o período compreendido entre a chegada de um morcego às plantas observadas até sua saída com o fruto. No caso de grupos foi considerado o período a partir da chegada do primeiro animal até a saída do último, e apenas quando pelo menos um indivíduo do grupo de fato tivesse retirado um fruto. Foram feitas fotografias com auxílio de flash, para análise mais detalhada do comportamento de abordagem e de retirada do alimento.

As coletas de morcegos foram feitas com redes de espera ("mist nets"), armadas em frente a árvores com frutos maduros. Os animais capturados eram mantidos vivos em sacos de pano por algumas horas. As suas fezes eram então recolhidas e os animais liberados. Alguns indivíduos foram mortos para confirmação de sua identidade e posteriormente depositados na coleção do Museu de História Natural da Universidade Estadual de Campinas (ZUEC). Os nomes específicos aqui utilizados estão de acordo com Wilson \& Reeder (1993). Foram também recolhidas fezes de morcegos com sementes de $V$. cayennensis encontradas sobre a folhagem, bem como as fezes de morcegos que defecavam enquanto nas redes. Foram conduzidos experimentos de germinação com sementes encontradas nas fezes de Carollia perspicillata (tratamento) e sementes retiradas de frutos maduros (controle). Em cada experimento foram utilizadas 100 sementes distribuídas em lotes de 25 sementes e colocadas em placas de Petri com papel de filtro umedecido com água destilada. As sementes nestas condições foram colocadas a germinar em local iluminado com luz natural por aproximadamente 11 horas por dia, sem controle de temperatura. A contagem das sementes germinadas foi feita a cada dois dias. Foram consideradas germinadas as sementes em que uma parte do embrião emergiu de dentro dos envoltórios. As sementes germinadas foram ainda observadas por alguns dias para se eliminar a possibilidade de falsa germinação (Labouriau 1983). O experimento foi encerrado depois de 30 dias, quando surgiram colônias de fungos e algumas sementes começaram a apodrecer. Para a comparação da germinabilidade das sementes do tratamento e do controle foi utilizado o "teste de igualdade de duas proporções" (Sokal \& Rohlf 1969). Para a comparação da velocidade de germinação das sementes do tratamento e do controle foi utilizado o teste de Kolmogorov-Smirnov (Sokal \& Rohlf 1969).

\section{Resultados}

Características da planta

Vismia cayennensis é uma espécie de hábito arbustivo-arbóreo, com indivíduos de cerca de $2 \mathrm{~m}$ de altura já frutificando, podendo atingir até cerca de $6 \mathrm{~m}$. Ocorre em áreas abertas (capoeiras), como clareiras e beira de mata, ao longo de trilhas e estradas. À época do estudo V. cayennensis apresentava frutos maduros. Seu caule é fino, os ramos espaçados entre si e paralelos ao solo (plagiotrópicos), lembrando uma estrutura em pagode (cf. van der Pijl 1972) e portando infrutescências terminais. Os frutos, tipo baga, são pequenos (Tabela 1), pendentes e expostos fora da folhagem. 
Apresentam forma ovalada e, antes do amadurecimento, são de cor verde, firmemente presos ao cálice e com látex de cor ferrugínea, que dá origem ao nome "lacre", pelo qual a planta é conhecida na região. As sementes são numerosas (Tabela 1), pequenas, de forma alongada e com uma testa dura. Uma série de processos que caracterizam o amadurecimento dos frutos ocorre em curto tempo, praticamente de um dia para o outro. Os frutos tornam-se intumescidos, com pequenas pintas castanho-escuras e com odor acre característico e forte. A quantidade de látex aparentemente diminui e os frutos soltam-se facilmente do cálice quando puxados. Sua polpa torna-se macia e suculenta, com sabor adocicado e a concentração de açúcares aumenta consideravelmente (Tabela 1). Poucos frutos amadurecem a cada noite.

Tabela 1. Características dos frutos de Vismia cayennensis na região de Manaus. $\overline{\mathrm{X}}=$ média; $\mathrm{s}=$ desvio padrão; $\mathrm{n}=$ número de frutos medidos.

\begin{tabular}{lccc}
\hline Características & $\overline{\mathrm{X}}$ & $\mathrm{s}$ & $\mathrm{n}$ \\
\hline $\begin{array}{l}\text { Maior comprimento do } \\
\quad \text { ruto maduro (cm) }\end{array}$ & 1,64 & 0,19 & 14 \\
$\begin{array}{l}\text { Maior largura do } \\
\quad \text { rruto maduro (cm) }\end{array}$ & 1,20 & 0,14 & 14 \\
$\begin{array}{l}\text { Massa do fruto maduro (g) } \\
\quad \text { Número de sementes }\end{array}$ & 1,51 & 0,50 & 11 \\
$\begin{array}{l}\text { Concentração de açúcares (\%) } \\
\quad \text { no pericarpo de frutos verdes }\end{array}$ & 9,30 & 41,31 & 13 \\
$\quad \begin{array}{l}\text { Concentração de açúcares (\%) } \\
\quad \text { no pericarpo de frutos maduros }\end{array}$ & 23,26 & 0,79 & 11 \\
\hline
\end{tabular}

Os morcegos

Foram capturados 10 indivíduos de Carollia perspicillata Linnaeus, três de Rhinophylla pumilio Peters, quatro de Sturnira tildae de la Torre, dois de Sturnira lilium Geoffroy, um de Artibeus (Koopmania) concolor Peters, e três de Artibeus lituratus Olfers nas redes armadas em frente a Vismia cayennensis. Destas espécies de Phyllostomidae, apenas nas fezes de A. lituratus não verificamos sementes de Vismia. As fezes de C. perspicillata revelaram também a presença de sementes de Solanum e Ficus.

Padrões de atividade alimentar

A quantificação da atividade alimentar dos morcegos foi feita numa noite sem luar. A atividade se manteve praticamente por toda a noite, sendo mais intensa na primeira metade da noite (Tabela 2). Neste período, as visitas tenderam a ser mais prolongadas e grupos maiores, de até nove indivíduos, foram registrados voando em 
torno e se alimentando nas plantas em observação. Nesta noite apenas três espécies de morcegos foram capturadas defronte às árvores de Vismia: C. perspicillata, S. lilium e A. concolor. Na segunda metade da noite a atividade persistiu, com número de visitas semelhante ao registrado para a porção anterior. Entretanto, as visitas foram consideravelmente mais curtas, tendo sido observados mais indivíduos solitários e grupos menores se alimentando.

Tabela 2. Padrões de visitas de morcegos filostomídeos a plantas de Vismia cayennensis com frutos maduros, na região de Manaus. Observações realizadas das 18:00 às 6:00 h.

\begin{tabular}{lll}
\hline Horário & $\begin{array}{l}\text { Número de } \\
\text { indivíduos } \\
\text { p/ visita }\end{array}$ & $\begin{array}{c}\text { Duração das } \\
\text { visitas (min) }\end{array}$ \\
\hline $19: 00$ & 4 & $3-5$ \\
$20: 30$ & 9 & 10 \\
$21: 25$ & $6-8$ & 5 \\
$22: 00$ & $5(2 \mathrm{spp})$ & $5-10$ \\
$22: 35$ & 4 & 5 \\
$22: 55$ & 4 & 10 \\
$23: 30$ & 3 & 5 \\
$00: 50$ & $5(2 \mathrm{spp})$ & $1-2$ \\
$01: 00$ & 3 & 1 \\
$01: 50$ & 3 & $1-2$ \\
$02: 30$ & 2 & 3 \\
$02: 50$ & 1 & $1-2$ \\
$03: 25$ & 3 & 2 \\
$03: 35$ & 1 & $1-2$ \\
$04: 20$ & $6(2 \mathrm{spp})$ & $5-10$ \\
$04: 55$ & 1 & $2-3$ \\
\hline
\end{tabular}

Comportamento alimentar

O comportamento alimentar dos morcegos durante as visitas a $V$. cayennensis obedeceu a um padrão básico e comum às diversas espécies observadas. Inicialmente, o morcego realiza uma série de vôos de aproximação em torno da planta, solitariamente ou em grupos. Aparentemente, neste vôo os morcegos fazem uma avaliação da disponibilidade e do estado dos frutos maduros na árvore, por vezes tocando os ramos e os próprios frutos. Se não houver frutos maduros, o animal abandona a planta, provavelmente em busca de outra fonte de alimento. Quando há frutos maduros, realiza a abordagem conforme uma das duas táticas descritas a seguir. Quando o fruto se acha exposto, o morcego realiza uma abordagem frontal. Após vôo direto ao fruto 
(Figura 1), o animal executa uma "freada" no ar e, virando de cabeça para baixo e sem se agarrar ao ramo, abocanha e arranca o fruto, com o auxílio dos polegares (Figura 2), deixando-se cair por alguns centímetros. Nesse momento recomeça a voar e, com o fruto na boca, dirige-se a um pouso de alimentação. A segunda tática de abordagem é realizada quando o acesso frontal ou por sobre o fruto é dificultado pela folhagem próxima. Neste caso, o morcego realiza um vôo ascendente até o fruto, o qual abocanha e, também com auxílio dos polegares e do peso do próprio corpo, arranca. Então deixa-se cair um pouco e retoma o vôo. Em ambas as situações, a abordagem e a retirada do fruto duraram apenas algumas frações de segundo. Não estudamos o comportamento dos morcegos nos pousos de alimentação, porém observamos fezes de morcegos com sementes de Vismia na folhagem ao longo de trilhas e na beira de estradas.

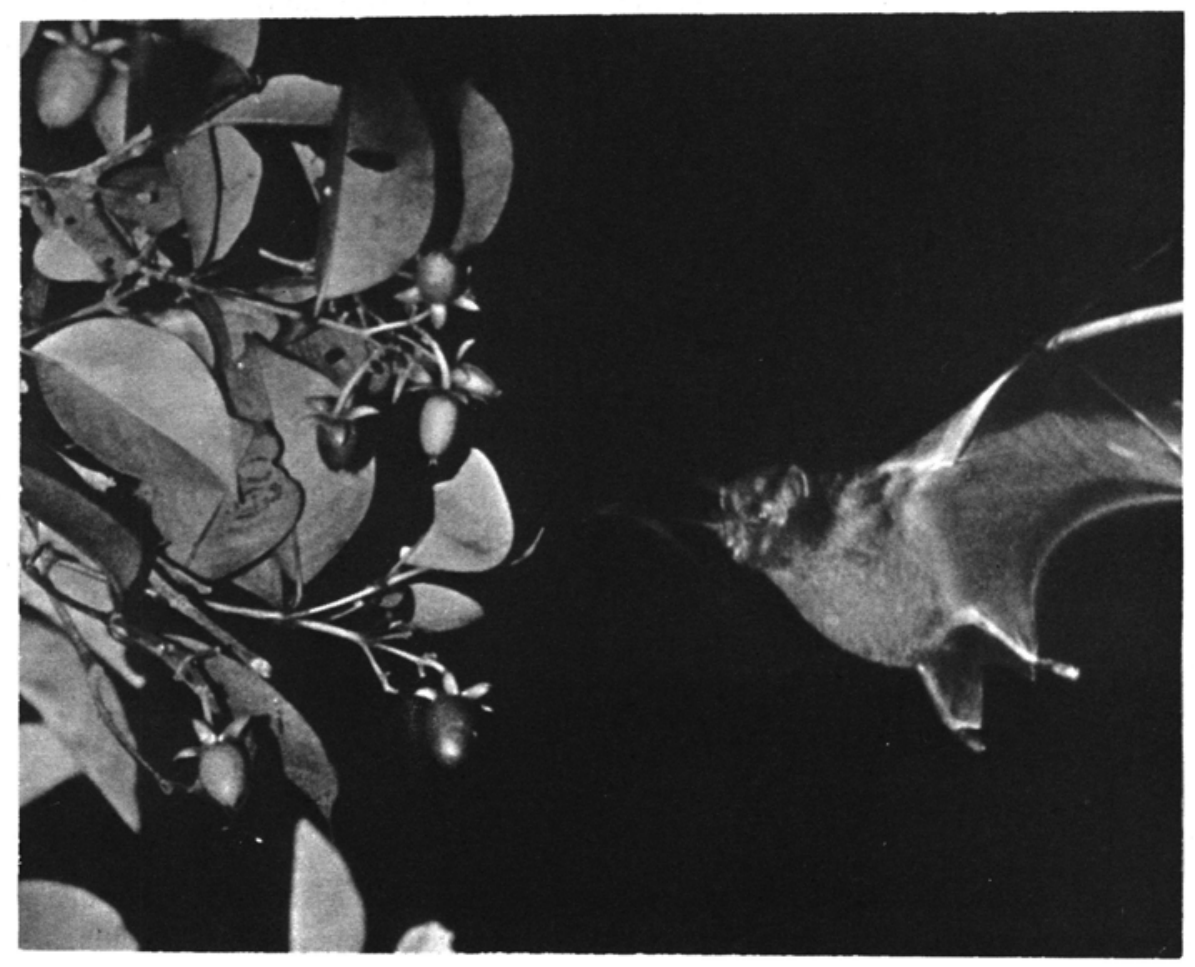

Figura 1. Artibeus (Koopmania) concolor durante aproximação frontal a um fruto maduro de Vismia cayennensis, na região de Manaus.

Não houve diferença significativa entre a germinabilidade das sementes retiradas das fezes de morcegos ( $56 \%$ das sementes germinaram) e das sementes retiradas de frutos maduros (53\% das sementes germinaram) $\left(t_{\mathrm{s}}=0,4260 ; \mathrm{P}>0,05\right)$. A 
germinação das sementes retiradas das fezes de morcegos (tratamento) começou no décimo dia do experimento, quando três sementes germinaram. No grupo controle a germinação começou um pouco mais cedo, no nono dia, quando apenas uma semente germinou. Entretanto, também não houve diferença significativa em relação à velocidade de germinação entre tratamento e controle (Kolmogorov-Smirnov $\mathrm{D}_{\max }=0,0839$ ; P > $>0,05)$.

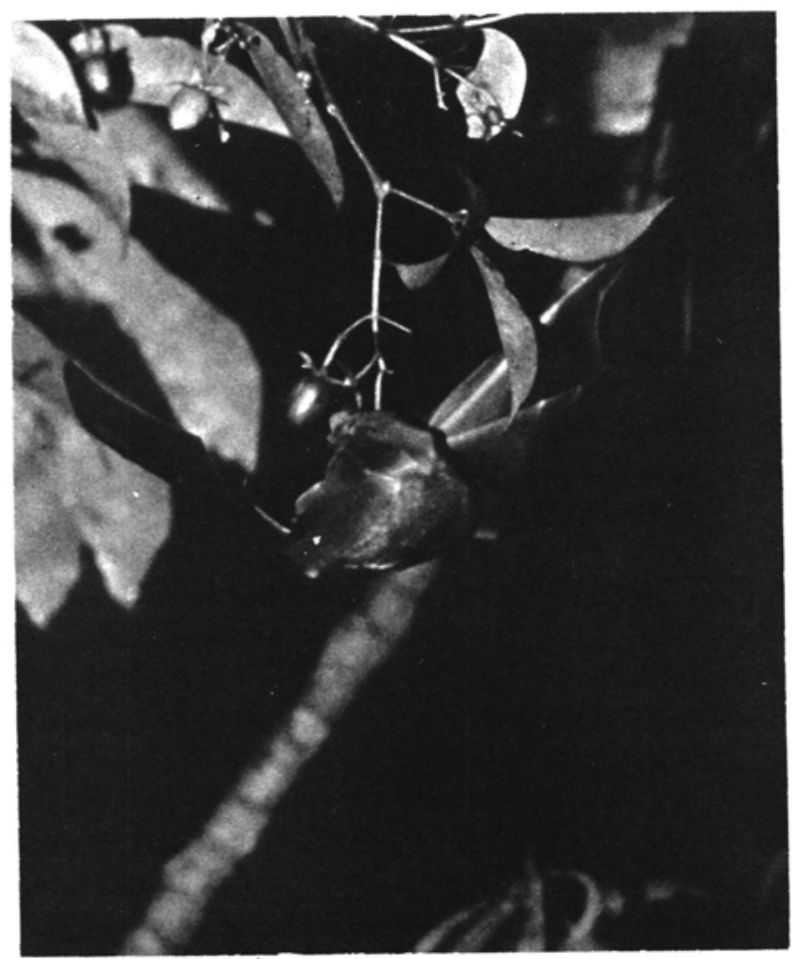

Figura 2. Carollia perspicillata ao virar de cabeça para baixo, para abocanhar e retirar fruto de Vismia cayennensis, na região de Manaus.

\section{Discussão}

Características da planta e sua relação com as características dos dispersores

A arquitetura da planta (estrutura em pagode), bem como o conjunto de atributos dos frutos (expostos fora da folhagem, permanentemente presos à planta, cor verde com pintas castanhas, odor acre e forte), correspondem à síndrome de quiropterocoria definida por van der Pijl (1972) e são características que facilitam a exploração de frutos de $V$. cayennensis por morcegos. Morcegos frugívoros são animais de visão limitada, sonar relativamente pouco desenvolvido, mas de olfato acurado e têm 
dificuldade em alcançar frutos no interior de folhagem densa (van der Pijl 1972). Todas as espécies de morcegos capturadas têm dieta basicamente frugívora (Gardner 1977) e, exceto A. lituratus, são espécies de porte pequeno a médio, com envergadura variando entre 25 e $30 \mathrm{~cm}$ e peso entre 14 e $25 \mathrm{~g}$, portanto capazes de carregar facilmente frutos inteiros de Vismia. Além destas espécies, Reis \& Guillaumet (1983) registram Artibeus jamaicensis e Phyllostomus discolor também utilizando Vismia sp na região de Manaus. O turgor dos frutos maduros, com liberação de odor, redução da quantidade de látex e o notável aumento da concentração de açúcares provavelmente correspondem a processos sincrônicos com a maturação das sementes e representam mecanismos para a atração e recompensa de um grupo restrito de animais, seus dispersores potenciais (Janzen 1983). Nesta ocasião as pequenas sementes maduras podem ser efetivamente dispersas, pois já apresentam uma testa capaz de resistir à passagem pelo tubo digestivo dos animais, sem sofrer danos.

Padrões de atividade e comportamento alimentar

Os padrões de atividade observados neste estudo são consistentes com aqueles descritos na literatura para morcegos frugívoros (e.g. Brown, 1968; Marinho-Filho \& Sazima, 1989). A atividade se mantém por toda a noite, sendo mais concentrada na primeira parte. Ainda que o número de visitas tenha sido semelhante tanto na primeira como na segunda parte da noite, a tendência a visitas mais demoradas e de grupos maiores na primeira metade da noite provavelmente indica uma maior disponibilidade de frutos maduros naquele período (Marinho-Filho \& Sazima 1989). Sazima \& Sazima (1977) observaram Phyllostomus discolor realizando visitas solitárias ou em grupos a flores de Lafoensia glyptocarpa e espécies de Bauhinia, em função da variação da oferta de recurso alimentar. As observações feitas no presente trabalho sugerem que um padrão semelhante pode ocorrer em relação à disponibilidade de frutos. No decorrer da noite, os frutos em boas condições vão sendo retirados e o comportamento de forrageio solitário ou em pequenos grupos pode ser uma estratégia mais favorável nesta circunstância.

Apesar da amostragem restrita, o aparente aumento de atividade observado pouco antes do amanhecer pode corresponder a um pequeno pico de atividade descrito na literatura para várias espécies de filostomídeos frugívoros, o qual tem sido associado a uma última refeição antes da volta aos abrigos diurnos (Brown, 1968; Marinho-Filho \& Sazima 1989).

O padrão básico de comportamento alimentar observado apresentou variação em relação à forma de abordagem dos frutos. Esta variação parece estar mais associada ao modo como se apresenta o fruto (mais exposto na porção terminal do ramo ou pendente e mais encoberto por folhas ou outros ramos) do que com características comportamentais de cada espécie de morcego, uma vez que todas apresentaram comportamento semelhante nas mesmas circunstâncias. Uieda \& Vasconcellos Neto (1985) também observaram essa relação para morcegos visitando Solanum asperum e Solanum grandiflorum. 
Não houve diferença significativa entre as taxas de germinação (germinabilidade) e nem na velocidade de germinação das sementes que passaram pelo tubo digestivo de Carollia perspicillata e as do controle. Isto, além das características das plantas e de seus padrões de distribuição, nas bordas de mata e trilhas, locais muito freqüentados por morcegos em suas rotas de alimentação, indicam que morcegos filostomídeos são os dispersores efetivos de Vismia cayennensis. Foresta et al. (1984) e Charles-Dominique (1986) indicam outras três espécies de Vismia existentes na Guiana Francesa como quiropterocóricas: V. guianensis, V. sessifolia e V. latifolia. Destas, pelo menos Vismia guianensis também ocorre em nossa área de estudo, na região de Manaus. As semelhanças morfológicas entre as árvores e frutos dessas espécies pioneiras de Vismia da região Amazônica e outras espécies do mesmo gênero, observadas em certas áreas da Floresta Atlântica do Espírito Santo (Reserva Florestal da Cia. Vale do Rio Doce em Linhares, obs. pessoal) e de Minas Gerais (Estação Biológica de Caratinga, comunicação pessoal de Ludmilla Aguiar), sugerem que estas também sejam dispersas por morcegos.

\section{Agradecimentos}

Agradecemos a Nélio Reis, Ivan Sazima, Wilson Uieda pelas sugestões e críticas e a Helena C. de Morais pela revisão do manuscrito; a Valdir A. Taddei pela identificação dos espécimes de Sturnira; ao Instituto Nacional de Pesquisas 'da Amazônia (INPA) e a Força Aérea Brasileira (FAB), pelo apoio logístico e transporte. O CNPq forneceu apoio financeiro a um dos autores (JMF).

\section{Referências bibliográficas}

Bonaccorso, F.J. 1979. Foraging and reproductive ecology in a Panamanian bat community. Bull. Fla. Mus. Biol. Sci. 24: 359-408.

Brown, J.H. 1968. Activity patterns of some neotropical bats. J. Mammal. 49: 754-757.

Carvalho, C.T. 1961. Sobre os hábitos alimentares de Phillostomideos (Mammalia, Chiroptera). Rev. Biol. Trop. 9: 53-60.

Charles-Dominique, P. 1986. Inter-relations between frugivorous vertebrates and pioneer plants: Cecropia, birds and bats in French Guyana. In Estrada, A. \& Fleming, T.H. (eds.) Frugivores and seed dispersal. Dordrecht: W. Junk. p. 119-135.

Foresta, H., Charles-Dominique, P., Erard, C. \& Prévost, M.F. 1984. Zoochorie et premier stades de la régénération naturelle après coupe en forêt guyanaise. Rev. Ecol. (Terre et Vie) 39: 369-400

Gardner, A. 1977. Feeding habits. In Baker, R.J., Jones, J.K. \& Carter, D.C. (eds.) Biology of bats of the New World family Phyllostomatidae, Part II. Spec. Publ. Mus. Texas Tech Univ. 13: 293-350.

Janzen, D.H. 1976. Ecology of plants in the tropics. Edward Arnold, London.

Janzen D.H. 1983. Dispersal of seeds by vertebrate guts. In Futuyma, D. \& Slatkin, M. (eds.) Coevolution. Sunderland: Sinauer. P.232-262

Laboriau, L.G. 1983. A germinação de sementes. Washington: OEA.

McKey, D. 1975. The ecology of coevolved seed dispersal systems. In Gilbert, L.E. \& Raven, P.H. (eds.) Coevolution of animals and plants. Austin: Univ. Texas. p. 159-191.

Marinho-Filho, J.S. 1990. The coexistence of two frugivorous bat species and the phenology of their food plants. J. Trop. Ecol. 7: 59-67. 
Marinho-Filho, J.S. \& Sazima, I. 1989. Activity patterns of six phyllostomid bat species in southeastern Brazil. Rev. Bras. Biol. 49: 777-782.

Reis, N.R. \& Guillaumet, J. 1983. Les chauve-souris frugivores de la région de Manaus et leur rôle dans la dissémination des espèces végétales. Rev. Ecol. (Terre et Vie) 38: 147-169.

Sazima, I. \& Sazima, M. 1977. Solitary and group foraging: two flower visiting patterns of the lesser spearnosed bat Phyllostomus discolor. Biotropica 9: 213-215.

Sokal, R.R. \& Rohlf, F.J. 1969. Biometry: New York: Freeman

Uieda, W. \& Vasconcellos-Neto, J. 1985. Dispersão de Solanum spp. (Solanaceae) por morcegos na região de Manaus, AM, Brasil. Rev. Bras. Zool. 2: 449-458.

van der Pijl, L. 1972. Principles of dispersal in higher plants. New York: Springer-Verlag.

Wilson, D.E, \& Reeder, D.M. 1993. Mammal species of the world; a taxonomic and geographic reference. Washington: Smithsonian Institution. 